\title{
Trenches for building blocks of advanced planar components
}

\section{Haiyan, Ou}

\section{Published in:}

I E E E Photonics Technology Letters

Link to article, DOI:

10.1109/LPT.2004.826052

Publication date:

2004

Document Version

Publisher's PDF, also known as Version of record

Link back to DTU Orbit

\section{Citation (APA):}

Haiyan, O. (2004). Trenches for building blocks of advanced planar components. I E E E Photonics Technology Letters, 16(5), 1334-1336. https://doi.org/10.1109/LPT.2004.826052

\section{General rights}

Copyright and moral rights for the publications made accessible in the public portal are retained by the authors and/or other copyright owners and it is a condition of accessing publications that users recognise and abide by the legal requirements associated with these rights.

- Users may download and print one copy of any publication from the public portal for the purpose of private study or research.

- You may not further distribute the material or use it for any profit-making activity or commercial gain

- You may freely distribute the URL identifying the publication in the public portal

If you believe that this document breaches copyright please contact us providing details, and we will remove access to the work immediately and investigate your claim. 


\title{
Trenches for Building Blocks of Advanced Planar Components
}

\author{
Haiyan $\mathrm{Ou}$
}

\begin{abstract}
Trenches are fundamental structures used to build advanced optical planar waveguide components. In this letter, the fabrication of trenches across silica-on-silicon waveguides using inductively coupled plasma etching is presented. These trenches were etched deep into the silicon substrate and their widths were varied between 24 and $100 \mu \mathrm{m}$. The insertion loss for waveguides with 24- and 28- $\mu \mathrm{m}$-wide trenches etched across them were measured for trenches filled with air and oil. The measured results followed those expected from simulations.
\end{abstract}

Index Terms-Hybrid integrated circuit fabrication, integrated optics, optical planar waveguides, waveguide component.

\section{INTRODUCTION}

$\mathbf{S}_{\mathrm{s}}$ ILICA-ON-SILICON optical waveguide components, such as splitters, directional couplers, and phased-array multi/demultiplexers are essential building blocks for future optical telecommunication networks. Silicon is an excellent substrate material for optical motherboards as it is mechanically robust, has good thermal properties, displays well-known and versatile electrical properties, and can be readily etched and micromachined [1]. The combination of silicon motherboards and planar silica waveguide technology allows hybridised optical subsystems to be manufactured at a low cost. The preferred way of making silica and silicon structures involves various plasma etching methods that are generally anisotropic and independent of crystal orientation [2]. When compared to other plasma etching technologies (e.g., electron cyclotron resonance, helicon, reactive ion etching (RIE), etc.), inductively coupled plasma (ICP)-based etch systems are often the preferred method for advanced deep etches with high aspect ratios due to their high etch rate and excellent selectivity when using conventional mask materials. This is mainly due to their greater scalability and wider operating windows [3]. Advanced oxide etch (AOE) and advanced silicon etch (ASE) both use a high plasma density and low-pressure (less than 10 mTorr) ICP, and therefore, are well suited to etch deep trenches with high aspect ratios, vertical profiles, good feature size control, and etch uniformity. Such precise and fast etch systems enable real optical hybridization at high yield and low manufacturing costs. Some examples include inserting filters into trenches to make low-cost wavelength-division-multiplexing modules [4] and using micromechanical optical switches integrated into

Manuscript received September 16, 2003; revised January 9, 2004.

The author is with the COM Centre, Technical University of Denmark, 2800

Kgs. Lyngby, Denmark (e-mail: ho@com.dtu.dk).

Digital Object Identifier 10.1109/LPT.2004.826052 the waveguide substrate that exploit thermocapillary action in very narrow trenches [5]. Additionally, with advanced etch technology capable of making tightly controlled deep narrow trenches, a new generation of compact low-index-contrast waveguide devices becomes practically realizable [6].

In this letter, deep trenches are etched through glass waveguides and the silicon substrates for these waveguides using AOE and ASE, respectively. The trenches have vertical and smooth sidewalls $\left(90^{\circ}\right.$ to $\left.92^{\circ}\right)$ and flat bottoms. The loss due to 24 and $28-\mu \mathrm{m}$-wide trenches without and with oil-filling across the waveguide is measured, simulated and compared. The small extra loss caused by the trenches indicate state-of-the-art AOE and ASE technology shows promise for the building blocks of advanced planar components.

\section{EXPERIMENTS}

Straight waveguide groups with widths ranging between 3 and $10 \mu \mathrm{m}$ in steps of $1 \mu \mathrm{m}$ were fabricated by plasma-enhanced chemical vapor deposition (PECVD) and RIE of germanium (Ge)-doped glass core layers [7]. The thickness of the core layer is $3.5 \mu \mathrm{m}$, and the refractive index step between the core and the cladding layer is 0.02 . This high index step waveguide would have about $2-\mathrm{dB}$ coupling loss with standard silica fibers.

Trenches with widths that varied between 24 and $100 \mu \mathrm{m}$ were etched across waveguides, also of varying widths, using ICP. The etch of deep trenches involves two steps. The first step is deep glass etching (the three waveguide layers: top-cladding, core, and buffer) using AOE, and the second step is a further etching to make deep trenches into the silicon substrate using ASE. Both AOE and ASE systems used were produced by Surface Technology Systems (STS) Limited.

The ASE process consists of a sequence of alternating etch and passivation cycle utilising $\mathrm{SF}_{6}$ and $\mathrm{C}_{4} \mathrm{~F}_{8}$ gases, respectively. The passivation phase deposits a fluorocarbon polymer over all surfaces of the wafer and trenches. During each etch cycle, the passivation is removed from the bottom of the etched features with the assistance of ion energy. The rest of the etch cycle is a short etch of the exposed $\mathrm{Si}$. The precursor gases comprise of $\mathrm{C}_{4} \mathrm{~F}_{8}, \mathrm{Ar}$, and $\mathrm{H}_{2}$ for AOE. Typically, a clean step is run after the deep oxide etch.

Five groups of waveguides were designed and were intersected by a varied number of trenches ranging from one to five. By measuring the insertion loss of the waveguides, the induced loss from the trenches was extracted. The experimental setup used to measure losses consists of a distributed feedback laser, a power meter, a polarization controller, and an 


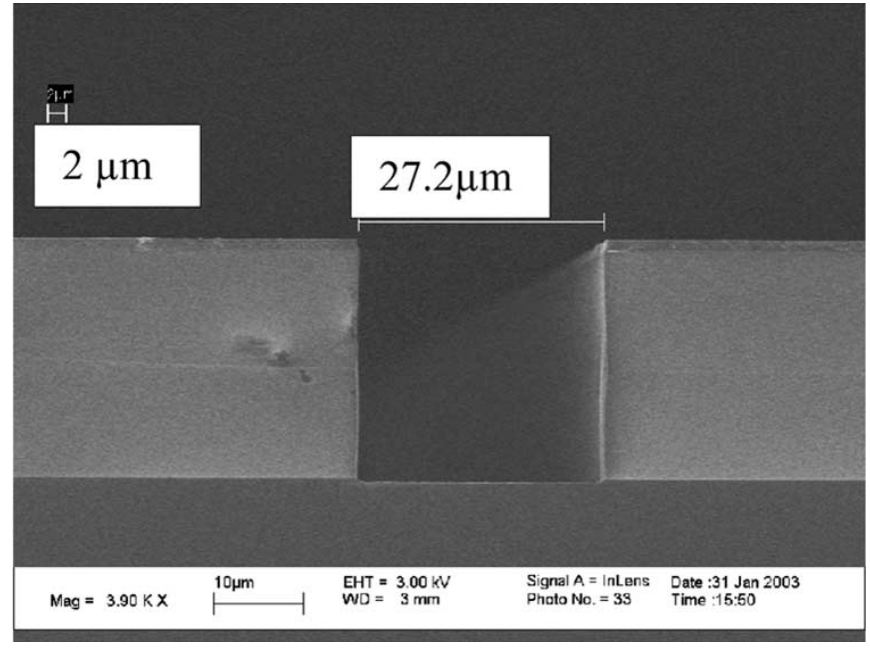

Fig. 1. Cross section of a 27.2- $\mu$ m-wide trench fabricated through AOE (with mask on) imaged using a scanning electron microscope (SEM).

optical spectral analyzer (OSA). The wavelength of the laser was $1557 \mathrm{~nm}$. The power meter and polarization controller with a computer interface can be used to measure the insertion loss and polarization-dependent loss. The OSA is for spectral analysis and monitored the transmission during the insertion loss measurement. The index matching oil used had a refractive index of 1.46 .

\section{RESULTS AND DISCUSSION}

A cross section of a $27.2-\mu$ m-wide trench across the waveguide fabricated through AOE is shown in Fig. 1. The total etch depth was $26.5 \mu \mathrm{m}$ which accommodates all three waveguide layers including $3.5-\mu \mathrm{m}$ core layer, $12-\mu \mathrm{m}$ buffer layer, and $11-\mu \mathrm{m}$ top-cladding layer. A 3- $\mu \mathrm{m}$-thick poly-silicon layer was deposited by low-pressure chemical vapor deposition on top of the waveguide and functioned as a mask. The etch rate was $0.5 \mu \mathrm{m} / \mathrm{min}$, and the selectivity to poly-silicon was about 30 . The sidewall was vertical $\left(90 \pm 0.5^{\circ}\right)$ and smooth. A slight traces of the interface between core and buffer layers of the waveguide can be seen from Fig. 1. A comparable process using RIE showed an etch rate of $0.24 \mu \mathrm{m} / \mathrm{min}$ and a selectivity of $6[8]$.

A cross section of a trench that has been etched further into the silicon substrate using ASE is shown in Fig. 2. When the trenches are etched through the waveguide layers into the silicon substrate, the top-cladding layer in the waveguide serves as the mask layer. The etch rate was $5.3 \mu \mathrm{m} / \mathrm{min}$, and the selectivity of silicon to glass was about 100. In comparison, a carefully optimized RIE process yields an etch rate of about $1.13 \mu \mathrm{m} / \mathrm{min}$, and a selectivity of about 12 [8]. As shown in Fig. 2, the etch depth in the silicon substrate was $96 \mu \mathrm{m}$, and the width was $27.5 \mu \mathrm{m}$. The sidewall of the trench is vertical $\left(90^{\circ}-92^{\circ}\right)$ and smooth and the bottom is also observed to be smooth with a little undercut.

It should be pointed out that deeper trenches with thicker waveguide layers can be etched while maintaining the same high quality by simply extending the total etch time.

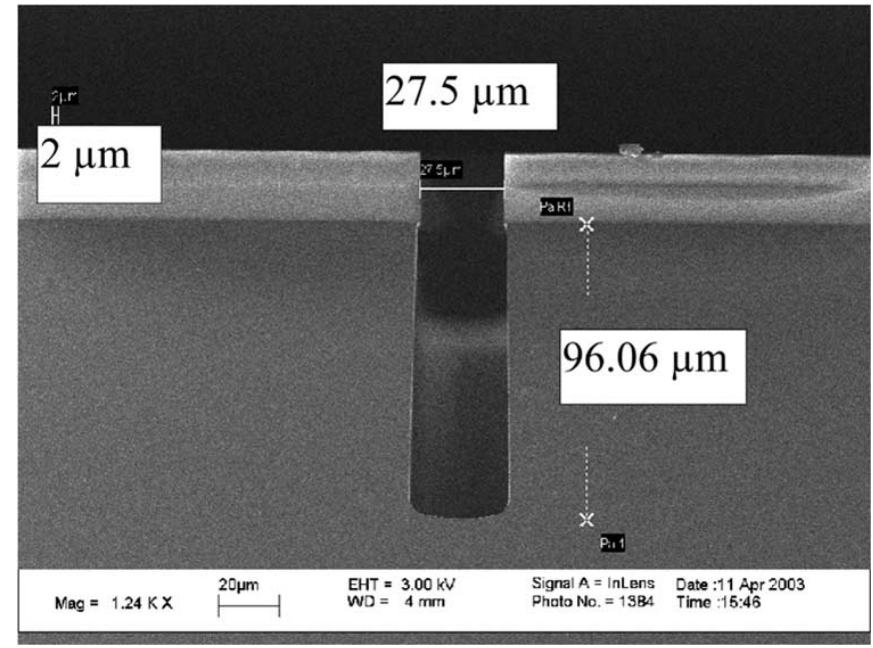

Fig. 2. Cross section of a further ASE-etched 27.5- $\mu$ m-wide trench about 96 $\mu \mathrm{m}$ deep into the silicon substrate imaged using SEM.

The insertion losses of waveguides with a varying number of trenches across them were measured for widths of 24 and $28 \mu \mathrm{m}$. The changes in insertion loss were measured when filling index matching oil into the trenches. These trench widths were selected because a polyimide half-wave plate and other polymer films (e.g., filters) usually have similar thicknesses. The results of the measurement before and after the filling of index matching oil for waveguides with $24-\mu \mathrm{m}$-wide trenches are shown in Fig. 3. Spurious data points due to waveguide breakage are removed from curves A and E. From Fig. 3, the extra loss of one $24-\mu \mathrm{m}$ air trench was measured to be $1.88 \mathrm{~dB}$. This loss decreased to 0.83 with the application of index matching oil. The extra loss of one $28-\mu \mathrm{m}$ air trench was $2.13 \mathrm{~dB}$, and $1.07 \mathrm{~dB}$ after the oil filling, corresponding to a loss reduction of $1.06 \mathrm{~dB}$. The extra loss is inconsequential when considering the additional functionality offered by the trenches. This is especially true since a cemented polyimide plate is likely to have approximately the same low loss as the oil-filled trenches. A simulation (based on the model in [9]) shows that a $24-\mu \mathrm{m}$-wide air trench causes extra loss of $1.34 \mathrm{~dB}$ and an oil trench of $0.68 \mathrm{~dB}$. A $28-\mu \mathrm{m}$-wide air trench brings 1.74-dB extra loss and an oil trench brings $0.90-\mathrm{dB}$ loss in theory. These theoretical values are probably smaller than measured because the model does not consider reflections at the interface. For the case of oil-filled trenches, measurement and simulation show an excellent agreement within the measurement accuracy. The simulation also indicates that the insertion loss of trenches increases with the increasing of the widths of trenches. Therefore, if functional film components have a thickness less than $24 \mu \mathrm{m}$, they can be inserted into a trench, across a waveguide, directly with a maximum insertion loss of $1 \mathrm{~dB}$. In this way, new subsystems such as optical isolators can be integrated to make hybrid systems. Very small trenches have found applications in compact waveguide components [6].

\section{CONCLUSION}

Trenches across buried planar waveguides were fabricated using AOE and ASE. These trenches were over $100 \mu \mathrm{m}$ deep 


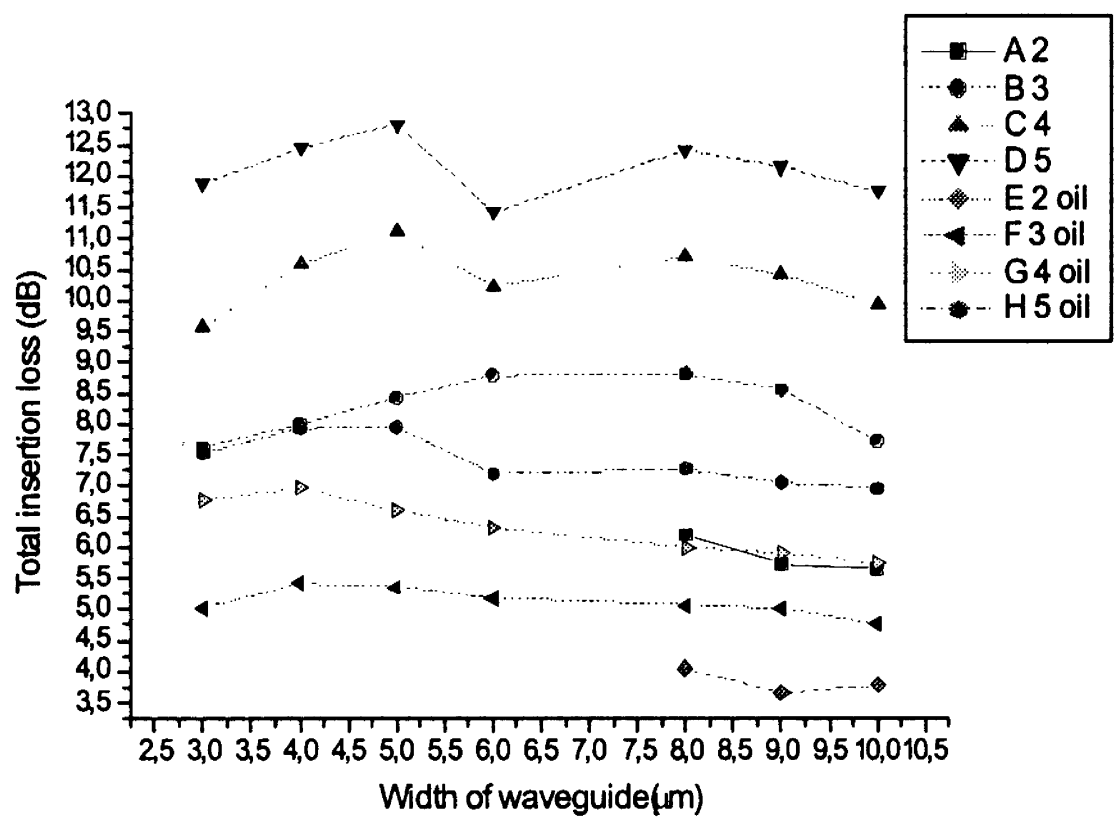

Fig. 3. Insertion loss of different width waveguides with a varying number of $24-\mu \mathrm{m}$-wide trenches—shown before and after filling the trenches with optical quality oil (index of 1.46) Note: Spurious data points are removed from curves A and E. A: Two trenches without oil-filling. B: Three trenches without oil filling. C: Four trenches without oil filling. D: Five trenches without oil filling. E: Two trenches with oil filling. F: Three trenches with oil filling. G: Four trenches with oil filling. H: Five trenches with oil filling.

and had smooth sidewalls. The etch rate of silica using AOE is $0.5 \mu \mathrm{m} / \mathrm{min}$, and the selectivity to poly-silicon is about 30. The etch rate of silicon using ASE is $5.3 \mu \mathrm{m} / \mathrm{min}$, and the selectivity to PECVD-deposited glass is about 100. The $\mathrm{AOE}$ and ASE are competent etch tools for hybrid integration of silica-on-silicon waveguide technology because of their high etch rate and anisotropic profile with high selectivity to traditional mask material. The excess loss caused by the introduction of one $24-\mu \mathrm{m}$-wide air trench is about $1.88 \mathrm{~dB}$, and the excess loss caused by one $28-\mu \mathrm{m}$-wide air trench is about $2.13 \mathrm{~dB}$. The excess loss was reduced to $0.83 \mathrm{~dB}$ for a $24-\mu \mathrm{m}$ trench and $1.07 \mathrm{~dB}$ for a $28-\mu \mathrm{m}$ trench after filling them with index matching oil. The measured values agree with the theoretical predictions. The small excess loss indicates there is promise in using these trenches to integrate multifunctional film components with silica-on-silicon waveguides.

\section{ACKNOWLEDGMENT}

The author would like to thank J. Hübner and H. Philipp for many fruitful discussion and comments. I. M. Castberg is acknowledged for her help in AOE. M. G. Dyndgaard is also thanked for the assistance in simulation.

\section{REFERENCES}

[1] C. A. Jones and K. Cooper, "Hybrid integration onto silicon motherboards with planar silica waveguides," in Proc. Inst. Elect. Eng.-Optoelectron., vol. 143, Oct. 1996, pp. 316-321.

[2] J. Bhardwaj, H. Ashraf, J. Hopkins, A. Hynes, I. Johnston, S. McCauley, S. Watcham, S. Hall, and G. Nicholls, "On inductively coupled plasma etching and HARMST," in Proc. 3rd Int. Conf. High Aspect Ratio Microstructure Technology, Kisarazu Chiba, Japan, 1999.

[3] S. A. McAuley, H. Ashraf, L. Atabo, A. Chambers, S. Hall, J. Hopkins, and G. Nicholls, "Silicon micromachining using a high-density plasma source," J. Phys. D, Appl. Phys., vol. 34, pp. 2769-2774, 2001.

[4] M. Ukechi, T. Miyashita, Y. Komine, T. Masa, A. Takahashi, T. Nishimura, R. Kaku, S. Hirayama, N. Uehara, and K. Ito, "A new concept for the WDM module using a waveguide equipped with filter," in Proc. Optical Fiber Communication (OFC), vol. 2, 2000, pp. 97-99.

[5] M. Makihara, M. Sato, F. Shimokawa, and Y. Nishida, "Micromechanical optical switches based on thermocapillary integrated in waveguide substrate," J. Lightwave Technol., vol. 17, pp. 14-18, Jan. 1999.

[6] L. Li, G. P. Nordin, J. M. English, and J. Jiang, "Small-area bends and beamsplitters for low-index-contrast waveguides," Opt. Exp., vol. 11, pp. 282-290, Feb. 2003.

[7] H. Ou, "Different index contrast silica-on-silicon waveguides by PECVD," Electron. Lett., vol. 39, pp. 212-213, Jan. 2003.

[8] - "Reactive ion etching in silica-on-silicon planar waveguide technology," in Proc. Eur. Conf. Optical Communication (ECOC), 2003, pp. 281-284.

[9] D. Marcuse, "Loss analysis of single-mode fiber splices," Bell Syst. Tech. J., vol. 56, pp. 703-718, May/June 1977. 